\title{
Sars-CoV-2 Induced Coagulopathy and Prognosis in Hospitalized Patients: A Snapshot from Italy
}

\author{
Betti Giusti ${ }^{1}$ Anna Maria Gori ${ }^{1}$ Manuel Alessi ${ }^{1}$ Angela Rogolino ${ }^{2}$ Elena Lotti ${ }^{2}$ Daniela Poli ${ }^{2}$ \\ Elena Sticchi ${ }^{1}$ Alessandro Bartoloni ${ }^{1}$ Alessandro Morettini ${ }^{2}$ Carlo Nozzoli ${ }^{2}$ Adriano Peris ${ }^{2}$ \\ Filippo Pieralli $^{2}$ Loredana Poggesi ${ }^{1}$ Niccolo Marchionni ${ }^{1}$ Rossella Marcucci ${ }^{1}$
}

\author{
${ }^{1}$ Department of Experimental and Clinical Medicine, University of \\ Florence, Florence, Italy \\ 2 Department of Cardiotoracovascolare, Azienda Ospedaliero- \\ Universitaria Careggi Firenze, Firenze, Italy
}

Thromb Haemost 2020;120:1233-1236.

After Wuhan, in China, Italy has become the European country with the highest number of cases and deaths by Sars-Cov-2. ${ }^{1,2}$

It has been reported from China the presence of altered coagulation parameters in a significant proportion of hospitalized patients. ${ }^{3-5}$ In addition, increased D-dimer (DD) levels have gained particular attention as predictors of acute respiratory distress syndrome development, the need of intensive care unit(ICU) admission, or death., ${ }^{6,7}$ It is well known that DD is a highly nonspecific marker which may be only the mirror of the clotting activation following the inflammatory process. ${ }^{8,9} \mathrm{Nev}$ ertheless, several thrombotic complications have been reported in patients with Covid-19 treated in ICU and the possible treatment with heparin appears to be very attractive. ${ }^{10}$

Before this therapeutic application, it is mandatory to verify and report to the scientific community which is the trend of coagulation parameters, so that we can accumulate several observations useful to design ad hoc interventional trials.

In this scenario, we decided to analyze the routine coagulation parameters-prothrombin time (PT), activated partial thromboplastin time (aPTT), DD, and platelet count-of a consecutive series of patients with documented infection by Sars-Cov-2 hospitalized in Careggi Hospital, Florence, Italy.

\section{Methods}

Two hundred and nine consecutive patients (133 males/76 females) with confirmed Sars-Cov-2 infection (according to the World Health Organization criteria), admitted to the Careggi Hospital, Florence, from March 2 to April 7, 2020, were enrolled. Exclusion criterion was the direct admission in ICU.

The clinical outcomes were monitored up to April 7, 2020 (median follow-up: 11 days [interquartile range [IQR]: 7-14]).

The results were given as mean \pm standard deviation or median (IQR), wherever appropriate. Distributed quantita-

Address for correspondence Rossella Marcucci, MD, PhD, Department of Experimental and Clinical Medicine, University of Florence, viale morgagni 85, Florence 50134, Italy

(e-mail: rossella.marcucci@unifi.it).

tive variables were compared using the Student's $t$-test and the Mann-Whitney $U$ test, as appropriate. A receiver operating characteristic (ROC) curve analysis was used to determine the ability of the analyzed parameters to distinguish between patients with different endpoints: death or hospital discharge. The optimal cut-off point was calculated by determining the level that provided the greatest sum of sensitivity and specificity.

\section{Results}

Thirty-one patients died (14.8\%) and 117 patients had been discharged (56\%). Fifty-one patients (24.4\%) have been transferred to an ICU. Eight thrombotic events were documented (3.8\%) in symptomatic patients, in the absence of routine compression ultrasound execution.

Laboratory values in the total population are reported in -Table 1.

We compared coagulation parameters at hospital admission between survivors versus nonsurvivors.

Nonsurvivor patients were older and, at hospital admission, they had significantly higher PT-international normalized ratio (INR), PT seconds, and mean platelet volume (MPV) values with respect to survivors ( $\mathbf{- T a b l e} \mathbf{1}$ ). No differences were detected in aPTT ratio and platelet count. ROC curves revealed that the cut-offs with the highest sensitivity and specificity for the endpoint "death" were: 1.40 for PT-INR, $1,000 \mathrm{ng} / \mathrm{mL}$ for DD, and $11.9 \mathrm{fL}$ for MPV. By defining "SarsCov-2 induced coagulopathy" as a combination of the three parameters (i.e., the presence of a value EQUAL or HIGHER than the reported cut-off for more than one parameter), area under the curve (AUC) increased to $0.78 \pm 0.06(p<0.05$; - Fig. 1A). The addition of the so-defined "Sars-Cov-2 induced coagulopathy," to a model that included age, which is "per se"

(c) 2020 Georg Thieme Verlag KG Stuttgart · New York
DOI https://doi.org/ $10.1055 / \mathrm{s}-0040-1712918$. ISSN 0340-6245. 
Table 1 Demographic and laboratory parameters of enrolled Sars-Cov-2 patients

\begin{tabular}{|c|c|c|c|c|c|c|c|}
\hline Variables & All $(n=209)$ & Alive $(n=178)$ & Dead $(n=31)$ & $p$-Values & $\begin{array}{l}\text { Discharged } \\
(n=117)\end{array}$ & $\begin{array}{l}\text { Nondischarged } \\
(n=92)\end{array}$ & p-Values \\
\hline Age, mean $\pm S D$ & $65.9 \pm 14.6$ & $63.5 \pm 14.0$ & $79.8 \pm 9.8$ & $<0.001$ & $59.9 \pm 14.0$ & $73.6 \pm 11.6$ & $<0.001$ \\
\hline Sex, M N (\%) & $133(63.6)$ & $112(62.9)$ & $21(67.7)$ & 0.607 & $74(63.2)$ & $59(64.1)$ & 0.895 \\
\hline PT, s & $14.0 \pm 2.5$ & $13.8 \pm 2.4$ & $15.2 \pm 3.1$ & 0.003 & $13.4 \pm 1.1$ & $14.8 \pm 3.5$ & $<0.001$ \\
\hline INR & $1.23 \pm 0.21$ & $1.22 \pm 0.21$ & $1.31 \pm 0.21$ & 0.002 & $1.18 \pm 0.10$ & $1.30 \pm 0.28$ & $<0.001$ \\
\hline aPTT ratio & $1.02 \pm 0.14$ & $1.02 \pm 0.14$ & $1.02 \pm 0.15$ & 0.858 & $1.00 \pm 0.09$ & $1.03 \pm 0.19$ & 0.786 \\
\hline $\begin{array}{l}\text { Platelet } \\
\text { count, } \times 10^{9} / \mathrm{L}\end{array}$ & $187(145-231)$ & 189 (149-233) & $\begin{array}{l}174 \\
(111-204)\end{array}$ & 0.127 & $\begin{array}{l}191 \\
(156-235)\end{array}$ & $\begin{array}{l}183 \\
(141-217)\end{array}$ & 0.088 \\
\hline MPV, fL & $\begin{array}{l}10.6 \\
(10.1-11.4)\end{array}$ & $\begin{array}{l}10.5 \\
(10.0-11.3)\end{array}$ & $\begin{array}{l}11.4 \\
(10.6-12.4)\end{array}$ & $<0.001$ & $\begin{array}{l}10.4 \\
(9.9-11.1)\end{array}$ & $\begin{array}{l}10.9 \\
(10.5-11.9)\end{array}$ & 0.001 \\
\hline $\begin{array}{l}\text { D-dimer, } \\
\mathrm{ng} / \mathrm{mL} \\
(n=135)\end{array}$ & $\begin{array}{l}794 \\
(513-1,247)\end{array}$ & $\begin{array}{l}739 \\
(498-1,160)\end{array}$ & $\begin{array}{l}1,149 \\
(757-2,049)\end{array}$ & 0.002 & $\begin{array}{l}669 \\
(490-960)\end{array}$ & $\begin{array}{l}969 \\
(550-1,670)\end{array}$ & 0.011 \\
\hline
\end{tabular}

Abbreviations: aPTT, activated partial thromboplastin time; M, males; INR, international normalized ratio; MPV, mean platelet volume; PT, prothrombin time; SD, standard deviation.

Note: Statistical significant values $(p<0.05)$ are depicted in bold.

1A. DEATH

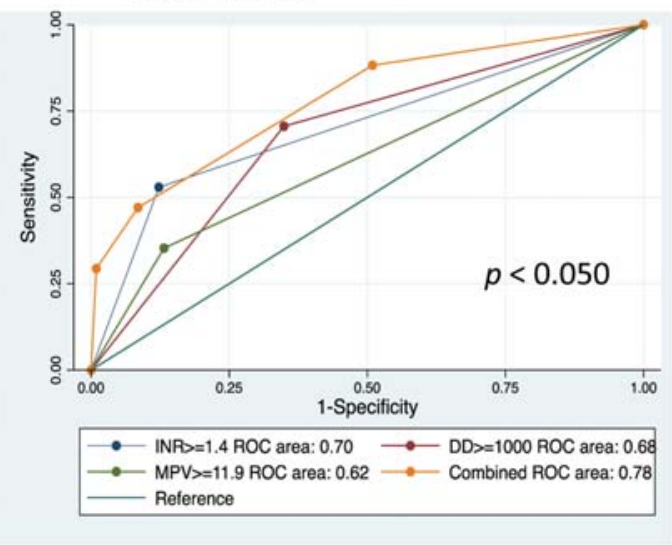

1C. DEATH

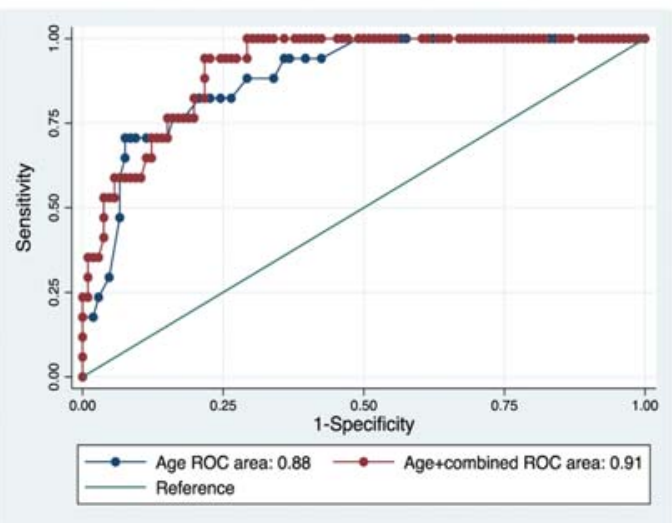

1B. HOSPITAL DISCHARGE

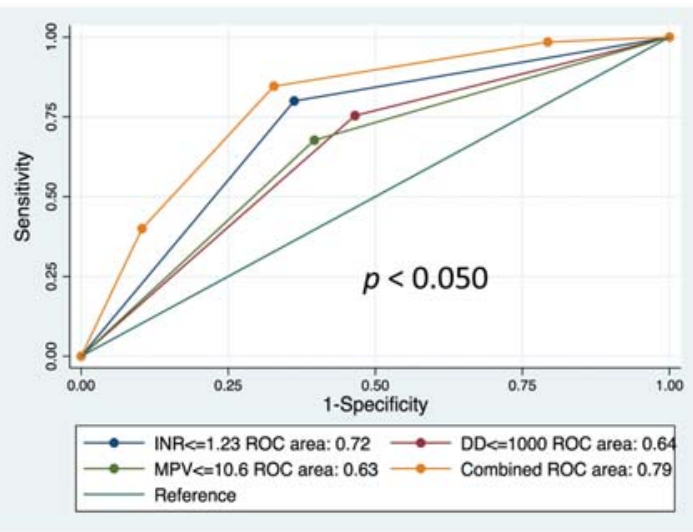

1D. HOSPITAL DISCHARGE

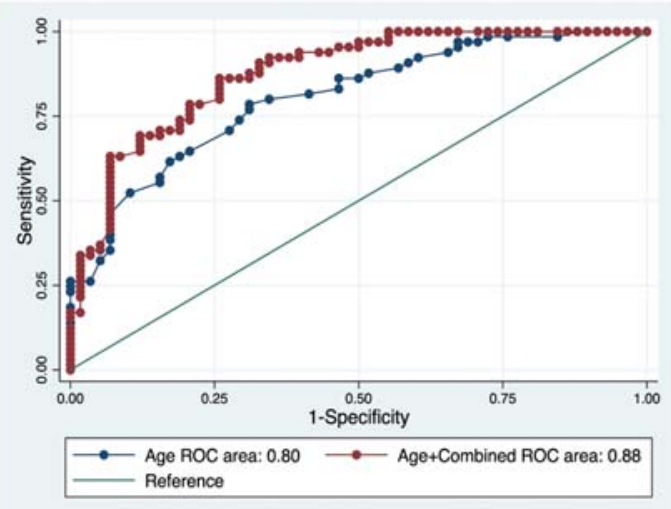

Fig. 1 Receiver operating characteristic (ROC) curves according to death and hospital discharged. ROC curves of PT-International Normalized Ratio (INR), D-dimer (DD) and Mean Platelet volume (MPV) according to death (1-A) and hospital discharge (1-B), when the three parameters were above (1-A) or below (1-B) the cut-off values. ROC curves for death of the two models of logistic regression: model 1 (age) or model 2 (age + combined coagulative parameters*) (1-C). ROC curves for hospital discharge of the two models of logistic regression: model 1 (age) or model 2 (age + combined coagulative parameters*) (1-D). 
a strong predictor of death (AUC $0.89 \pm 0.04$ ), slightly increased the AUC $(0.92 \pm 0.03 ; p=0.10)$ for the detection of death (-Fig. 1C). At multivariate regression analysis, adjusted for age and sex, age and Sars-Cov2-induced coagulopathy were independent predictors of death (age: odds ratio $[\mathrm{OR}]=1.17,95 \%$ confidence interval $[\mathrm{CI}] 1.07-1.27$; $p<0.0001 /$ Sars-Cov2-induced coagulopathy: $\mathrm{OR}=2.72$, $95 \%$ CI 1.20-6.17; $p=0.016$ ).

In addition, we compared coagulation parameters at hospital admission between discharged versus nondischarged patients. Discharged patients were younger and, at admission, had significantly lower PT-INR, PT seconds, DD, and MPV values with respect to the others ( - Table $\mathbf{1}$ ). No differences were detected in aPTT ratio and platelet count. ROC curves revealed that the cut-offs with the highest sensitivity and specificity for the endpoint "hospital discharge" were: 1.23 for PT-INR, $1,000 \mathrm{ng} / \mathrm{mL}$ for DD, and $10.6 \mathrm{fL}$ for MPV. By defining "NO Sars-Cov-2 induced coagulopathy" as a combination of the three parameters (i.e., the presence of a value LOWER than the reported cutoff for more than one parameter), AUC increased to $0.79 \pm 0.04(p<0.05 ;$ - Fig. 1B). By adding the "NO SarsCOv-2 induced coagulopathy" to a model that included age, which is "per se" a strong predictor of hospital discharge (AUC $0.80 \pm 0.04$ ), significantly increased the AUC $(0.88 \pm 0.03 ; p=0.016)$ for the detection of hospital discharge (-Fig. 1D).

\section{Discussion}

These results demonstrate that patients at hospital admission for Sars-Cov-2 infection often have an alteration in the routine coagulation parameters. In particular, PT-INR, DD, and MPV are the three parameters which, together with age, resulted to be significantly associated with death and discharge, so allowing us to identify two clusters of inpatients with worse or better prognosis.

In particular, the absence, at hospital admission, of an involvement in clotting and fibrinolytic pathways identifies a group of patients at low risk of complications.

We think that the most relevant result is that this score not only maintains but increases the AUC for death or discharge if associated with age, which is "per se" the strongest clinical predictor of outcome.

It is well known that thrombosis is associated with inflammation and vice versa. ${ }^{11,12}$ In the model of sepsis, it has just been validated as score (SIC - sepsis-induced coagulopathy score) in which PT-INR, fibrinogen, and platelet count are associated with a worse prognosis. In the setting of SarsCov-2 infection, it has been demonstrated that both clotting activation and fibrinolysis are crucial. ${ }^{13-18}$ Indeed, our data demonstrate that also DD levels help us to identify patients at higher or lower risk. In addition, in our group, platelet size and not platelet count is significantly associated with clinical outcomes: we know that MPV is a marker of platelet function as it is positively associated with indicators of platelet activity, including aggregation and release of thromboxane A2, platelet factor 4 , and b-thromboglobulin. ${ }^{19,20}$
A subsequent step might be a clinical trial designed to randomize patients with "Sars-Cov-2 coagulopathy" to an intensive antithrombotic treatment, to verify a possible impact on prognosis. Possible intervention in this area might be heparin treatment at intermediate or therapeutic dosage or other treatment able to interfere with the inflammatory process as suggested by the study of Tang et al. ${ }^{6}$

A limitation of this study is the limited number of patients recruited from a single center; in addition, some patients are still hospitalized at the time of manuscript submission.

Nonetheless, these data suggest a possible clinical utility of a score based on routine coagulation parameters to stratify the prognosis of hospitalized patients with Sars-Cov-2 infection.

Conflict of Interest

None declared.

\section{References}

$1 \mathrm{Wu} Z$, McGoogan JM. Characteristics of and important lessons from the coronavirus disease 2019 (COVID-19) outbreak in China: summary of a report of 72-314 cases from the Chinese Center for Disease Control and Prevention. JAMA 2020. Doi: 10.1001/jama.2020.2648

2 Istituto Superiore di Sanità. Characteristics of COVID-19 patients dying in Italy. Report based on available data on March 30th, 2020. Available at: https://www.epicentro.iss.it/coronavirus/bollettino/ Report-COVID-19_30_marzo_eng.pdf. Accessed April 1, 2020

3 Guan WJ, Ni ZY, Hu Y, et al; China Medical Treatment Expert Group for Covid-19. Clinical characteristics of coronavirus disease 2019 in China. N Engl J Med 2020;382(18):1708-1720

4 Tang N, Li D, Wang X, Sun Z. Abnormal coagulation parameters are associated with poor prognosis in patients with novel coronavirus pneumonia. J Thromb Haemost 2020;18(04):844-847

5 Huang C, Wang Y, Li X, et al. Clinical features of patients infected with 2019 novel coronavirus in Wuhan, China. Lancet 2020; 395:497506

6 Tang N, Bai H, Chen X, Gong J, Li D, Sun Z. Anticoagulant treatment is associated with decreased mortality in severe coronavirus disease 2019 patients with coagulopathy. J Thromb Haemost 2020;18(05):1094-1099

7 Han H, Yang L, Liu R, et al. Prominent changes in blood coagulation of patients with SARS-CoV-2 infection. Clin Chem Lab Med 58(7): $1116-1120$

8 Rodelo JR, De la Rosa G, Valencia ML, et al. D-dimer is a significant prognostic factor in patients with suspected infection and sepsis. Am J Emerg Med 2012;30(09):1991-1999

9 Semeraro F, Ammollo CT, Caironi P, et al. D-dimer corrected for thrombin and plasmin generation is a strong predictor of mortality in patients with sepsis. Blood Transfus 2019:1-8

$10 \mathrm{Li} \mathrm{X}, \mathrm{Ma}$ X. The role of heparin in sepsis: much more than just an anticoagulant. Br J Haematol 2017;179(03):389-398

11 Jackson SP, Darbousset R, Schoenwaelder SM. Thromboinflammation: challenges of therapeutically targeting coagulation and other host defense mechanisms. Blood 2019;133(09):906-918

12 Iba T, Levy JH. Inflammation and thrombosis: roles of neutrophils, platelets and endothelial cells and their interactions in thrombus formation during sepsis. J Thromb Haemost 2018;16 (02):231-241

13 Claushuis TAM, de Stoppelaar SF, Stroo I, et al. Thrombin contributes to protective immunity in pneumonia-derived sepsis via fibrin polymerization and platelet-neutrophil interactions. J Thromb Haemost 2017;15(04):744-757

14 Burzynski LC, Humphry M, Pyrillou K, et al. The coagulation and immune systems are directly linked through the 
activation of interleukin- $1 \alpha$ by thrombin. Immunity 2019;50(04): 1033-1042

15 de Stoppelaar SF, van 't Veer C, van der Poll T. The role of platelets in sepsis. Thromb Haemost 2014;112(04):666-677

16 Vardon-Bounes F, Ruiz S, Gratacap MP, Garcia C, Payrastre B, Minville V. Platelets are critical key players in sepsis. Int J Mol Sci 2019;20(14):E3494

17 Assinger A, Schrottmaier WC, Salzmann M, Rayes J. Platelets in sepsis: an update on experimental models and clinical data. Front Immunol 2019;10:1687
18 Gralinski LE, Bankhead A III, Jeng S, et al. Mechanisms of severe acute respiratory syndrome coronavirus-induced acute lung injury. MBio 2013;4(04):e00271-e13

19 Gasparyan AY, Ayvazyan L, Mikhailidis DP, Kitas GD. Mean platelet volume: a link between thrombosis and inflammation? Curr Pharm Des 2011;17(01):47-58

20 Slavka G, Perkmann T, Haslacher H, et al. Mean platelet volume may represent a predictive parameter for overall vascular mortality and ischemic heart disease. Arterioscler Thromb Vasc Biol 2011;31(05):1215-1218 